\title{
Single Nucleotide Variants (SNVs) Define Senescence-Accelerated SAMP8 Mice, a Model of a Geriatric Condition
}

\author{
Fabien Delerue $^{\mathrm{a}}$, Geoff Sjollema ${ }^{\mathrm{b}}$, Belinda Whittle ${ }^{\mathrm{b}}$, Sarah Krüger ${ }^{\mathrm{a}}$, Dan Andrews ${ }^{\mathrm{b}}$ \\ and Jürgen Götz ${ }^{\mathrm{a}, \mathrm{c}, *}$ \\ ${ }^{a}$ Brain and Mind Research Institute, University of Sydney, Camperdown, NSW, Australia \\ ${ }^{\mathrm{b}}$ Australian Phenomics Facility (APF), John Curtin School of Medical Research, Australian National University, \\ Acton, ACT, Australia \\ ${ }^{\mathrm{c} C e n t r e ~ f o r ~ A g e i n g ~ D e m e n t i a ~ R e s e a r c h ~(C A D R) ~ a t ~ t h e ~ Q u e e n s l a n d ~ B r a i n ~ I n s t i t u t e ~(Q B I), ~}$ \\ The University of Queensland, Brisbane, QLD, Australia
}

Handling Associate Editor: Michal Novak

Accepted 20 March 2013

\begin{abstract}
One of the major challenges in neurodegenerative research is modeling systemic aging. Here, senescence-accelerated mice such as the multigenic SAMP8 (senescence accelerated prone 8) mice are useful as they are characterized by an early manifestation of senescence that includes a shortened lifespan and impaired brain and immune functions. While SAMP8 mice are widely used tools to address aging and neurodegenerative conditions such as Alzheimer's disease (AD), the underlying gene mutations are not known. To make the SAMP8 strain a more versatile and useful research tool, we performed exome sequencing, using SAMR1 (senescence accelerated mouse resistant 1) mice as controls. We identified 51 SNVs (single nucleotide variants) that discriminate SAMP8 from SAMR1 mice. Using the prediction tool Polyphen2, we were able to subdivide the SNVs into four categories: splice variants, probably damaging, possibly damaging, and benign. Of these genes, a significant fraction is predicted to be expressed in the brain. Our data present these genes for a more detailed analysis in aging and neurodegeneration studies. They underscore the usefulness of SAMP8 mice as an animal model to study fundamental mechanisms of both aging and the pathogenesis of $\mathrm{AD}$.
\end{abstract}

Keywords: Alzheimer's disease, exome sequencing, mouse, senescence, sequence nucleotide variants

\section{INTRODUCTION}

Aging is the major risk factor for a plethora of human diseases. This includes Alzheimer's disease (AD), a neurodegenerative disorder that is characterized by a progressive decline in memory and other cognitive

\footnotetext{
*Correspondence to: Jürgen Götz, Centre for Ageing Dementia Research (CADR), Queensland Brain Institute (QBI), The University of Queensland, Brisbane, QLD 4072, Australia. Tel.: +61 73346 6329; Fax: +61 73346 6301; E-mail: j.goetz@uq.edu.au.
}

functions, leading to dementia [1]. To better understand the underlying pathogenic mechanisms and to develop targeted therapies, a host of transgenic animal models has been developed that reproduce amyloid plaques and neurofibrillary tangles, the two brain lesions characteristic of the human condition [2]. A prerequisite for developing these lesions in mice has been the transgenic expression of the tau-encoding $M A P T$ or the amyloid- $\beta$ protein precursor (A $\beta P P$ )-encoding $A \beta P P$ gene together with pathogenic mutations that are 
present in early-onset familial cases. The vast majority of AD cases, however, are of late onset and hence, transgenic models do not faithfully model these sporadic cases. Here, senescence-accelerated mice such as the SAMP8 (senescence accelerated prone 8) strain might be useful, as these mice display many features known to occur early in the pathogenesis of $\mathrm{AD}$, such as increased oxidative stress and memory impairment [3]. SAMP8 mice are therefore an excellent model for studying the earliest neurodegenerative changes associated with $\mathrm{AD}$, providing a more encompassing picture of human disease, a syndrome that is triggered by a combination of age-related events [4].

Together with a series of related senescenceaccelerated mice, the SAMP8 strain was established around 1975 by conventional inbreeding of AKR/Jderived mice that displayed features of accelerated aging such as hair loss, reduced activity, shortened life expectancy, lordokyphosis (increased curvature of the spine), and periophthalmic (around the eye) problems [5]. Littermates of mice that did not show a senescence-associated phenotype were also inbred, and senescence-resistant, longer-lived SAMR mice were obtained of which SAMR1 (senescence accelerated mouse resistant 1) mice are commercially available. SAMP strains exhibit an early onset of age-related decline in the peripheral immunity such as thymic involution, loss of CD4(+) T cells, impaired helper $\mathrm{T}$ cell function, decreased antibodyforming capacity, dysfunction of antigen-presenting cells, decreased natural killer activity, increased autoantibodies, and susceptibility to viral infection [6].

SAMP8 mice have been extensively analyzed for cognitive functions [7]. Impairment of spatial memory is initiated at the age of four months, as shown by using various forms of water and radial arm mazes [8-10]. By employing the more sensitive radial arm water maze, impairments in spatial learning became evident as early as three months of age [11]. In measuring associative memories, fear conditioning or passive avoidance tasks are widely used [12, 13]. In SAMP8 mice, while associative learning as assessed in the fear conditioning-paradigm is not affected, both passive and active avoidance (i.e., learning to escape the environment in which the aversive stimulus has been received) are affected, with an age of onset as early as two months [14, 15].

SAMP8 mice are neuropathologically characterized by oxidative changes similar to those found in the AD brain [16]. For example, key enzymes that detoxify reactive oxygen species such as MnSOD, catalase or glutathione peroxidase are all decreased in SAMP8 compared to SAMR1 mice [17-19]. Increased lipid peroxidation and carbonyl damage is present as early as 2 months of age [20]. Furthermore, SAMP8 mice have an impaired glucose metabolism [21], and reveal agedependent reductions of various receptors including for NMDA [22]. Because in the AD brain, deposition of $A \beta$ leads to plaque formation and that of the microtubule-associated protein tau to tangle formation, these two process have been extensively analyzed in SAMP8 mice [23]. Tau was found to be hyperphosphorylated using a small set of phosphorylation site-specific antibodies, but tau filament formation and tangle formation has not been reported indicating that the SAMP8 mice present with an early rather than a more advanced tau pathology [23]. In phosphorylating tau and causing its aggregation [24], studies in SAMP8 mice suggest a role for the kinases GSK3 and Cdk5 [25]. Staining with A $\beta$-specific antibodies suggested $A \beta$ deposition in the mice $[26,27]$; however because different from the human sequence of $\mathrm{A} \beta \mathrm{PP}$, the murine protein lacks the amino acids that are required to generate $A \beta$ in the first place, these deposits have been termed 'A $\beta$-like' [26]. For A $\beta P P$, age-related increases have been reported, both at the protein and mRNA level [28-30]. Finally, a glial pathology characterizes the aging brain and in particular, the AD brain, and not surprisingly, SAMP8 mice present with a marked astro- and microgliosis [30, 31]. These findings present SAMP8 mice as a suitable model for aging dementia, thereby complementing the existing transgenic mouse models.

However, a major drawback in making the best use of senescence-accelerated mice is that their phenotype is multigenic and that the underlying gene mutations are not known. Therefore, we obtained SAMP8 mice from a commercial breeder and phenotypically characterized them. To make the SAMP8 model more suitable for geriatric studies, we performed massively parallel exome sequencing [32]. By applying this method to SAMP8 and SAMR1 mice, we were able to identify 51 SAMP8-specific single nucleotide variants (SNVs), followed by a Polyphen 2 analysis that allows phenotype predictions.

\section{MATERIALS AND METHODS}

\section{Animals}

SAMP8/TaHsd (in short: SAMP8) and SAMR1/ TaHsd (in short: SAMR1) mice were obtained from Harlan Laboratories UK Ltd. They were rederived by 
embryo transfer followed by expansion of a colony in the SPF unit of our institute's animal facility. Animal experimentation was approved by the Animal Ethics Committee (AEC) of the University of Sydney (approval number K00/1-2009/3/4914).

\section{Phenotypic analysis and histology}

The weight of the mice was monitored on a weekly basis. Immunohistochemical staining for glial fibrillar acidic protein (GFAP) was done on $3 \mu \mathrm{m}$ sections of paraformaldehyde-fixed and paraffin-embedded brain tissue of 6 month-old mice as described [33]. More specifically, brains were fixed in paraformaldehyde and embedded in paraffin using an Excalibur tissue processor (Thermo). Antigen retrieval was done in a temperature- and pressure-controlled microwave system (Milestone) in Tris/EDTA $\mathrm{pH} 9.0$ for $7 \mathrm{~min}$ at $120^{\circ} \mathrm{C}$, followed by cooling under running tap water for $10 \mathrm{~min}$. Primary antibody anti-GFAP (monoclonal IgG, Sigma, \#63893) was diluted 1:100 in blocking buffer (heat inactivated 3\% normal goal serum, $2 \%$ BSA, $0.1 \%$ Tween-20 in $1 \times$ PBS) and incubated overnight at $4^{\circ} \mathrm{C}$. After three washes in $1 \times \mathrm{PBS}$, the sections were incubated with an Alexa-coupled secondary antibody (Invitrogen, \#A-11001) for $1 \mathrm{~h}$ at room temperature, followed by three washes in $1 \times$ PBS. The sections were then mounted in Fluoromount medium (Sigma \# F4680) and digital images taken with a BX51 fluorescent microscope (Olympus).

\section{Exome sequencing}

Exome enriched, paired end libraries were prepared from genomic DNA of two SAMP8 and two SAMR1 mice following the protocol 'SureSelect Target Enrichment System for Illumina Paired-End Multiplexed Sequencing library' (v1.1.1, November 2010, Agilent). The Illumina Paired-end genomic DNA sample prep kit (PE-102-1001, Illumina) was used for preparing the libraries including end repair, A-tailing, and ligation of the Illumina adaptors. For capture, SureSelect Mouse exome baits (G7550, Agilent) were used to enrich for the mouse exome. Each sample was prepared with an index in an amplification step following capture using the Illumina multiplexing sample preparation oligo-nucleotide kit (PE-400-1001, Illumina). Enriched sample libraries were pooled in equimolar batches of three and each batch run as $100 \mathrm{bp}$ paired end libraries on the Illumina HiSeq 2000 sequencer.

\section{Data analysis}

Sequence reads were mapped to the NCBIM37 assembly of the reference mouse genome using Burrows-Wheeler Aligner (http://bio-bwa.sourceforge .net) [34]. Untrimmed reads were aligned allowing a maximum of two sequence mismatches and were discarded where they aligned to the genome more than once. Sequence variants were identified with SAMtools (http://samtools.sourceforge.net) [35] and annotated using Annovar (http://www.openbioinforma tics.org) [36]. A version of PolyPhen2 (http://genetics. bwh.harvard.edu/pph2) [37], adapted for the mouse, was utilized for the calculation of the variant effect.

\section{Validation of single nucleotide variants}

SNVs identified by Next Generation Sequencing were validated using the Amplifluor SNP genotyping system (Chemicon, Millipore). Assays were designed to each SNV of interest and validated against a set of Samp8 and SamR1 mice. Primer sequences for each SNV that has been assayed can be found in the Supplementary Table 1 (available online: http://dx.doi.org/10.3233/JAD-130089).

\section{RESULTS}

Phenotypic characterization of SAMP8 mice

To phenotypically characterize SAMP8 mice and differentiate them from SAMR1 mice, we determined the lifespan of both strains. According to Harlan from whom we had obtained the mice, the median survival time of SAMP8 mice is 12.1 months whereas SAMR1 mice have a median survival time of 18.9 months. Others reported a mean lifespan of 9.7 months for SAMP mice (not specifying the sub-strain) and 16.3 months for SAMR mice, while standard inbred mouse strains (such as C57Bl/6) have a life expectancy in the order of 28 months [4]. In agreement with previous data, we found that SAMP8 mice displayed an increased mortality compared to SAMR1 mice (Fig. 1A), and gained less weight as they aged (Fig. 1B). At six months of age, using immunohistochemistry, we did not find evidence for amyloid plaque formation in the SAMP8 compared to the SAMR1 mice using the 4G8 antibody, nor did we find pronounced differences in tau phosphorylation using antibodies 12E8, AT180, or AT8 (data not shown). However, what we found at this age was a 
A

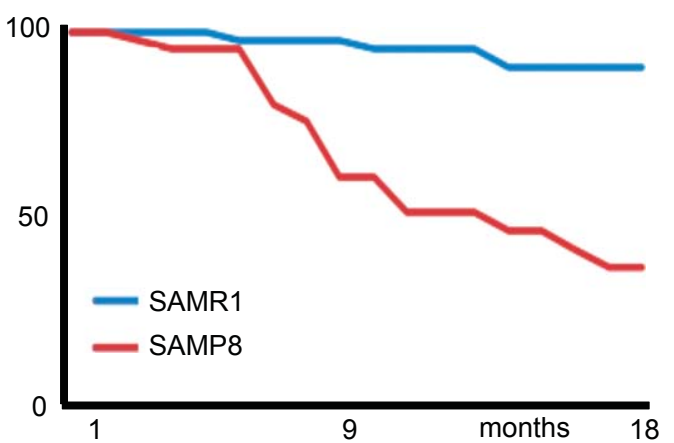

C

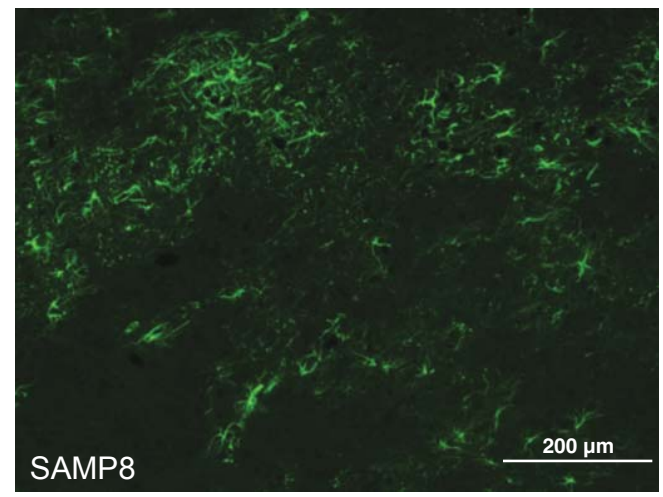

B
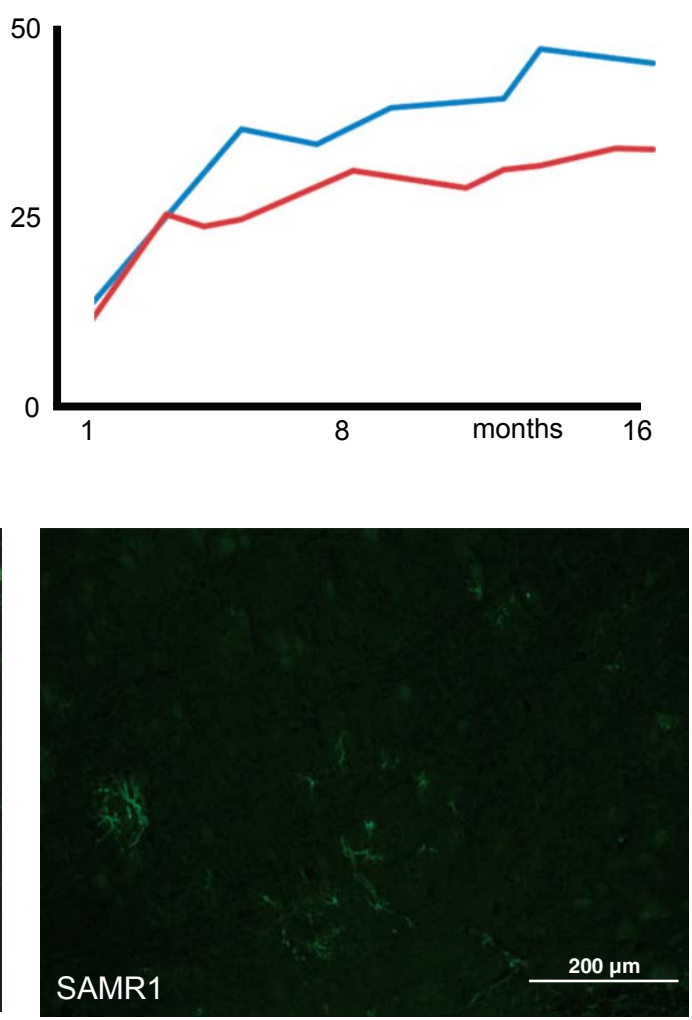

Fig. 1. Phenotypic characterization of SAMP8 mice. A) SAMP8 have an increased mortality compared to SAMR1 mice, (B) they are characterized by a reduced weight gain due to reduced body musculature, and (C) already at an age of 6 months reveal pronounced astrogliosis as evidenced by GFAP immunoreactivity. The pons is shown. For comparison, both strains revealed astrogliosis in the hippocampus but not the cortex.

pronounced astrogliosis in the pons of SAMP8 compared to SAMR1 mice (Fig. 1C). In the hippocampus, the two strains showed a similar degree of astrogliosis, while cortical areas were, in our hands, virtually free of activated astrocytes (data not shown). Phenotypically, by three to four months of age, SAMP8 mice can be discriminated from SAMR1 mice based on their reduced weight (Fig. 1B), a slightly hunched position, skin coarseness, and partial alopecia, as shown for 6 month-old mice (Fig. 2A).

\section{Exome sequencing of SAMP8 and SAMRI DNA}

To identify genes with a putative role in the SAMP8 phenotype, we performed exome sequencing of two SAMP8 and SAMR1 mice each. Exome enrichment allowed us to successfully sequence $85-90 \%$ of the CCDS exome to a high level of coverage. From this sequencing, we found $226 \mathrm{SNVs}$ that were common between the two SAMP8 mice and not seen in either SAMR1 mice or in any previous sequencing effort
(>250 exomes, mostly C57B1/6). By removing olfactory and vomeronasal genes to eliminate a large subset of possible SNV call errors due to the high sequence homology amongst these gene family members, and excluding genes with multiple SNVs (also indicating short-read alignment errors rather than mutations) the list was reduced to 113 SNVs.

Of the 113 SNVs, 105 were selected for validation using a specific Amplifluor assay to each SNV on a larger pool of SAMP8, SAMR1, C57B1/6, and AKR/J control samples ( 8 assays could not be designed with primers of sufficient quality). Of the 103 SNVs, 37 were shared with the AKR/J control strain (i.e., a polymorphism between the $\mathrm{C} 57 \mathrm{Bl} / 6$ reference genome and the control AKR/J sample), 13 assays failed, 2 were shown to be heterozygous and unique to SAMP8, 1 was a false positive, 1 was homozygous in the SAMP8 strain and heterozygous in all controls, and 51 SNVs were unique to SAMP8 (Table 1). We found that the SNVs were found on all chromosomes but 9, 16, and Y. Most SNVs were found on chromosome 8 (a total 


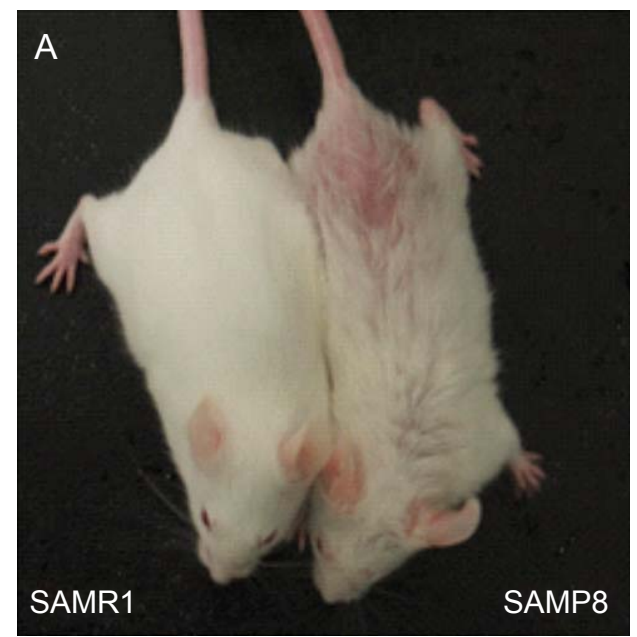

C

Splice

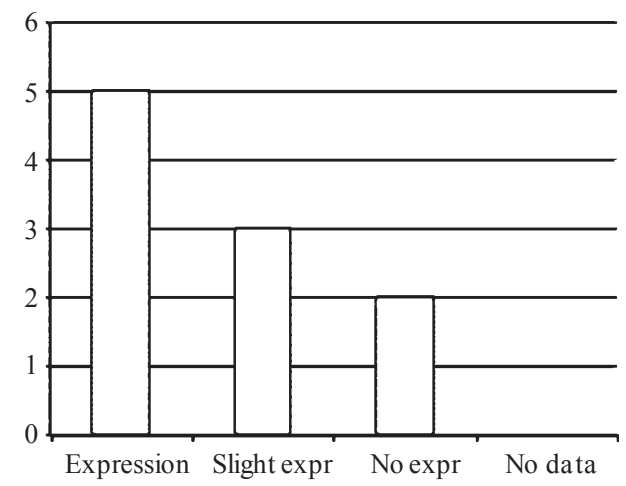

Possibly damaging

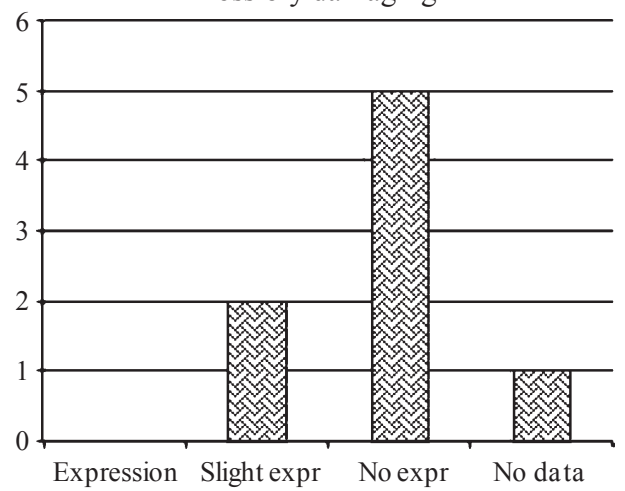

B

Polyphen2 prediction

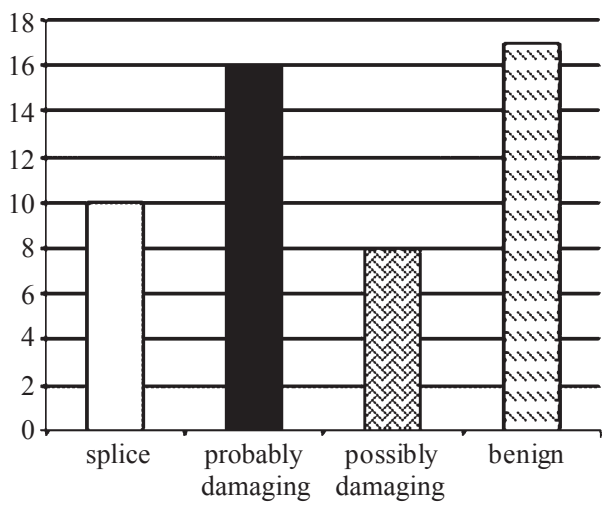

Probably damaging

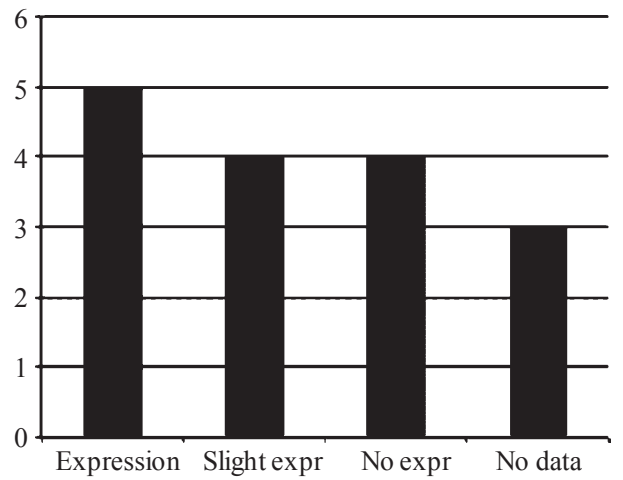

Benign

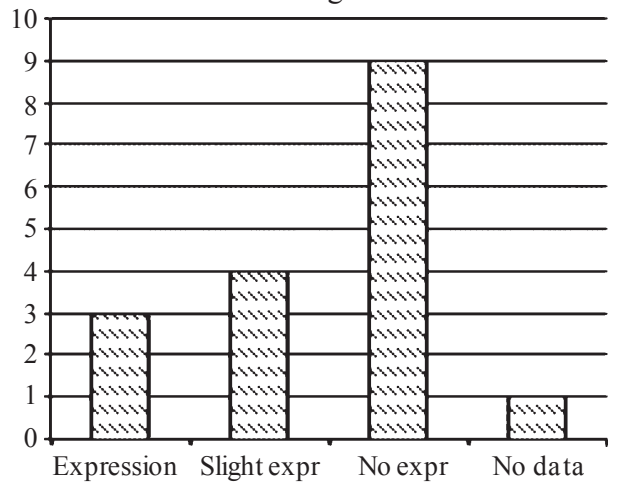

Fig. 2. Phenotype predictions. A) Partial alopecia shown for 6 month-old SAMP8 compared to SAMR1 mouse. B) Of the 51 SNVs that we identified as being unique to SAMP8, 10 are possible splice variants, while 41 are within the coding sequence. According to the amino acid substitution prediction tool Polyphen2, of the 41 coding variants, 24 are possibly or probably damaging (confidence of $0.5-1.0$ ), while 17 are probably benign (confidence $<0.5$ ). C) By consulting the Allen brain atlas, the four groups are either moderately or strongly expressed in brain, not expressed or there are no data available. 
of ten), followed by chromosome 13 (five SNVs), and 4, 7, 10, and 19 (with four SNVs each).

\section{Polyphen prediction of SAMP8-specific single nucleotide variants and brain-specific expression of SAMP8 genes}

Of the 51 SNVs that we identified as being unique to SAMP8, 10 are possible splice variants (intronic mutations located within 10 base pairs of the exon boundary), while 41 are within the coding sequence. According to the amino acid substitution prediction tool Polyphen2, of the 41 coding variants, 24 are possibly or probably damaging (confidence of $0.5-1.0$ ), while 17 are probably benign (confidence $<0.5$ ) (Table 1, Fig. 2B). The genes with SNVs have multiple functions as suggested by a Gene Ontology (GO) analysis (Table 2).

21 of the genes have an OMIM entry and 11 have a reported phenotype in mice with a null mutation (Table 2). By consulting the Allen brain atlas (Allen Brain Atlas [Internet]. Seattle (WA): Allen Institute for Brain Science. Copyright (C) 2009. Available from: http://www.brain-map.org), we found that within the first category (splice variants), 8 of 10 genes are expressed in brain, while for 2 no expression was reported (Table 3, Fig. 2C). For the second category (probably damaging SNVs), for three genes, no data are available, four are not expressed in brain, and nine are expressed in brain, ranging from very slight to high expression levels, and from a restricted expression pattern to expression throughout the brain (Fig. 2C). For the third category (possibly damaging), no data is available for one gene; and 7 genes are listed as being expressed in brain. For the fourth category (benign), for 1 no data are available on brain expression, 5 are not expressed in brain, and 2 are slightly expressed in brain (Fig. 2C). Overall, the data indicate that at least 50\% of all identified genes may have a function in the brain (Fig. 2). Whether the SNVs cause changes in levels of the encoded proteins, in their subcellular localization, association with other proteins and/or in their activity, remains to be determined in subsequent studies.

\section{DISCUSSION}

Characterized by a range of age-associated impairments, which includes the nervous system, senescenceaccelerated SAMP8 mice present themselves as an excellent geriatric model [38]. We confirmed that SAMP8 mice die prematurely and that they display a reduced weight gain compared to SAMR1 mice.
Astrogliosis has been suggested as a useful marker to discriminate, at a pre-symptomatic age, the two strains; however, we found this less reliable as in our studies astrogliosis depended on the brain area investigated, with both strains showing a similar degree of activation in the hippocampus, while SAMR1 mice showed a much lesser degree of astrogliosis in the pons compared to SAMP8 mice.

We also performed exome sequencing and identified 51 SNVs (mutations) that are unique to SAMP8 mice, using senescence-resistant SAMR1 mice as well as the two inbred strains $\mathrm{C} 57 \mathrm{Bl} / 6$ and AKR/J (from which SAMR1 and SAMP8 have been originally derived [5]) as controls. 10 of the SNVs are possible splice variants; 41 are within the coding sequence. Using the prediction tool Polyphen2, we identified 24 of the 51 SNVs as being either probably or possibly damaging. In coming up with these predictions, it is not only the type of amino acid that is critical but also where it sits in relation to the different domains, such as binding and active sites. Interestingly, not all A-T SNVs are benign, as is the case, e.g., for SLC12A4.

As evidenced by GO analysis, the mutated genes encode proteins with a wide range of cellular functions. These include ion transport, cytokine activity, axonogenesis, heme binding, GTP binding, protein transport, and others. 21 of the genes have an OMIM entry and 11 have a reported phenotype in mice with a null mutation. Consulting the Allen brain atlas revealed that a significant fraction is expressed in the brain, often with a regional pattern and ranging from very low to pronounced expression levels. Overall, the data indicate that at least $50 \%$ of all identified genes have a function in the brain.

When we analyzed the genes with brain expression in more detail and restricted the analysis to those SAMP8 SNVs for which the Polyphen tool either made no predictions or predicted that they are 'probably or possibly damaging', we identified several gene products that are worth being discussed in the context of the known SAMP8 brain phenotype: APBA3 (also known as Mint3) encodes an adapter protein that is part of the X11 protein family. Interestingly, APBA3 interacts with $A \beta P P$ from which $A \beta$ is derived by proteolytic cleavage. More recently APBA3 has been identified as a mediator of $A \beta P P$ signaling: Its interaction with a set of transcriptional co-activators was shown to lead to nuclear localization and transactivation, whereas an interaction of the same set with Mint1 or Mint2 prevented nuclear localization and transactivation [39]. There is increasing evidence that in AD gene regulatory networks are deregulated [40]: In the current 
Table 1

SAMP8-specific mutations and Polyphen predictions. Exome sequencing identified 51 SNVs in the genes indicated that are unique to SAMP8. Mutations were found on all chromosomes (chr) but 9, 16, and Y. Coord (coordinate); snp id (SNP ID); ref b (nucleotide on B6 background); var b (nucleotide variant in SAMP8); aa change (amino acid change caused by variant); Polyphe prediction (such as: probably damaging); Polyph. score (Polyphen score: confidence of $0.5-1.0$ for probably damaging); snp exon type (splice versus coding variants); ens name (Ensemble Gene

\begin{tabular}{|c|c|c|c|c|c|c|c|c|c|c|c|}
\hline Gene name & $\mathrm{chr}$ & coord & snp_id & ref $b$ & var b & aa change & $\begin{array}{l}\text { Polyphen } \\
\text { prediction }\end{array}$ & $\begin{array}{l}\text { Polyph. } \\
\text { score }\end{array}$ & $\begin{array}{l}\text { snp } \\
\text { exon type }\end{array}$ & ens name & ccds name \\
\hline SYT11 & 3 & 88565645 & 3Т88565645 & $\mathrm{C}$ & $\mathrm{T}$ & N/A & N/A & N/A & SPLICE & ENSMUSG00000068923 & CCDS38484 \\
\hline ARFIP2 & 7 & 112786848 & 7A112786848 & G & A & N/A & N/A & N/A & SPLICE & ENSMUSG00000030881 & CCDS21656 \\
\hline TPP1 & 7 & 112895447 & 7T112895447 & $\mathrm{C}$ & $\mathrm{T}$ & N/A & N/A & N/A & SPLICE & ENSMUSG00000030894 & CCDS21661 \\
\hline NAE1 & 8 & 107054400 & $8 \mathrm{C} 107054400$ & $\mathrm{~T}$ & $\mathrm{C}$ & N/A & N/A & N/A & SPLICE & ENSMUSG00000031878 & CCDS40452 \\
\hline TMEM208 & 8 & 107850365 & $8 \mathrm{~T} 107850365$ & $\mathrm{C}$ & $\mathrm{T}$ & N/A & N/A & N/A & SPLICE & ENSMUSG00000014856 & CCDS22599 \\
\hline EDC4 & 8 & 108405065 & 8G108405065 & $\mathrm{C}$ & G & N/A & N/A & N/A & SPLICE & ENSMUSG00000036270 & CCDS52662 \\
\hline CNTNAP4 & 8 & 115305415 & $8 \mathrm{~T} 115305415$ & $\mathrm{C}$ & $\mathrm{T}$ & N/A & N/A & N/A & SPLICE & ENSMUSG00000031772 & CCDS40482 \\
\hline PARP8 & 13 & 117727545 & $13 \mathrm{C} 117727545$ & G & $\mathrm{C}$ & N/A & N/A & N/A & SPLICE & ENSMUSG00000021725 & CCDS36790 \\
\hline 6720463M24RIK & 14 & 99467789 & 14G99467789 & $\mathrm{T}$ & G & N/A & N/A & N/A & SPLICE & ENSMUSG00000022070 & CCDS27309 \\
\hline KLF12 & 14 & 100386793 & 14A100386793 & G & A & N/A & N/A & N/A & SPLICE & ENSMUSG00000072294 & CCDS36998 \\
\hline SLC12A4 & 8 & 108475720 & $8 \mathrm{~T} 108475720$ & $\mathrm{C}$ & $\mathrm{T}$ & $A->T$ & probably damaging & 1 & NON-SYN & ENSMUSG00000017765 & CCDS22623 \\
\hline APBA3 & 10 & 80733977 & $10 C 80733977$ & G & $\mathrm{C}$ & $\mathrm{D}->\mathrm{H}$ & probably damaging & 1 & NON-SYN & ENSMUSG00000004931 & CCDS24050 \\
\hline PQLC3 & 12 & 17000350 & $12 \mathrm{C} 17000350$ & A & $\mathrm{C}$ & $\mathrm{S}->\mathrm{R}$ & probably damaging & 1 & NON-SYN & ENSMUSG00000045679 & CCDS49032,CCDS25824 \\
\hline TMEM55B & 14 & 51547625 & 14A51547625 & G & A & $\mathrm{R}->\mathrm{W}$ & probably damaging & 1 & NON-SYN & ENSMUSG00000035953 & CCDS27028 \\
\hline D15ERTD621E & 15 & 58274396 & $15 T 58274396$ & $\mathrm{C}$ & $\mathrm{T}$ & $\mathrm{P}->\mathrm{S}$ & probably damaging & 1 & NON-SYN & ENSMUSG00000037119 & CCDS37080 \\
\hline DNAHC8 & 17 & 30944165 & 17G30944165 & A & G & $\mathrm{D}->\mathrm{G}$ & probably damaging & 1 & NON-SYN & ENSMUSG00000033826 & CCDS37541 \\
\hline F830016B08RIK & 18 & 60459876 & $18 \mathrm{~A} 60459876$ & G & A & $\mathrm{D}->\mathrm{N}$ & probably damaging & 1 & NON-SYN & ENSMUSG00000090942 & CCDS50297 \\
\hline FXN & 19 & 24355043 & $19 \mathrm{~T} 24355043$ & $\mathrm{C}$ & $\mathrm{T}$ & G->R & probably damaging & 1 & NON-SYN & ENSMUSG00000059363 & CCDS29711 \\
\hline PTPRD & 4 & 75590897 & $4 \mathrm{~T} 75590897$ & $\mathrm{C}$ & $\mathrm{T}$ & $\mathrm{E}->\mathrm{K}$ & probably damaging & 0.999 & NON-SYN & ENSMUSG00000028399 & CCDS18289 \\
\hline SPCS2 & 7 & 106993250 & 7T106993250 & $\mathrm{C}$ & $\mathrm{T}$ & $\mathrm{D}->\mathrm{N}$ & probably damaging & 0.999 & NON-SYN & ENSMUSG00000035227 & CCDS40033 \\
\hline IRS2 & 8 & 11006858 & $8 A 11006858$ & G & A & $\mathrm{P}->\mathrm{S}$ & probabl ydamaging & 0.999 & NON-SYN & ENSMUSG00000038894 & CCDS52477 \\
\hline ODZ2 & 11 & 35920361 & 11A35920361 & $\mathrm{C}$ & A & $\mathrm{C}->\mathrm{F}$ & probably damaging & 0.999 & NON-SYN & ENSMUSG00000049336 & CCDS24546 \\
\hline HBB-BH2 & 7 & 110988898 & 7A110988898 & G & A & $\mathrm{T}->\mathrm{M}$ & probably damaging & 0.997 & NON-SYN & ENSMUSG00000078621 & CCDS52340 \\
\hline ANKRD2 & 19 & 42114907 & 19A42114907 & G & A & $\mathrm{G}->\mathrm{R}$ & probably damaging & 0.997 & NON-SYN & ENSMUSG00000025172 & CCDS50437 \\
\hline 4930506M07RIK & 19 & 59049495 & 19A59049495 & G & A & $\mathrm{T}->\mathrm{M}$ & probably damaging & 0.977 & NON-SYN & ENSMUSG00000041362 & CCDS50481 \\
\hline TESK1 & 4 & 43456467 & $4 \mathrm{~T} 43456467$ & $\mathrm{G}$ & $\mathrm{T}$ & $\mathrm{C}->\mathrm{F}$ & probably damaging & 0.975 & NON-SYN & ENSMUSG00000028458 & CCDS18094 \\
\hline D630023F18RIK & 1 & 65163738 & 1A65163738 & $\mathrm{C}$ & A & $E->D$ & possibly damaging & 0.946 & NON-SYN & ENSMUSG00000044816 & CCDS15015 \\
\hline PRL8A9 & 13 & 27650078 & $13 \mathrm{C} 27650078$ & $\mathrm{~T}$ & $\mathrm{C}$ & $\mathrm{Y}->\mathrm{C}$ & possibly damaging & 0.933 & NON-SYN & ENSMUSG00000006490 & CCDS26400 \\
\hline PCDH7 & 5 & 58111277 & 5A58111277 & G & A & $\mathrm{V}->\mathrm{M}$ & possibly damaging & 0.899 & NON-SYN & ENSMUSG00000029108 & CCDS19296,CCDS51505 \\
\hline IFNA2 & 4 & 88329388 & 4A88329388 & $\mathrm{G}$ & A & $A->V$ & possibly damaging & 0.852 & NON-SYN & ENSMUSG00000078354 & CCDS18326 \\
\hline ARHGEF5 & 6 & 43238765 & $6 \mathrm{~A} 43238765$ & G & A & $\mathrm{V}->\mathrm{I}$ & possibly damaging & 0.776 & NON-SYN & ENSMUSG00000033542 & CCDS51759 \\
\hline LRRC20 & 10 & 60945213 & $10 \mathrm{~T} 60945213$ & G & $\mathrm{T}$ & $\mathrm{S}->\mathrm{I}$ & possibly damaging & 0.707 & NON-SYN & ENSMUSG00000037151 & CCDS23881 \\
\hline ZC3H12D & 10 & 7587218 & $10 \mathrm{~T} 7587218$ & $\mathrm{C}$ & $\mathrm{T}$ & $\mathrm{P}->\mathrm{L}$ & possibly damaging & 0.564 & NON-SYN & ENSMUSG00000039981 & CCDS48496 \\
\hline 1700019N19RIK & 19 & 58860749 & 19T58860749 & G & $\mathrm{T}$ & Q->K & possibly damaging & 0.55 & NON-SYN & ENSMUSG00000026931 & CCDS38031 \\
\hline
\end{tabular}


Table 1

(Continued)

\begin{tabular}{|c|c|c|c|c|c|c|c|c|c|c|c|}
\hline Gene name & $\mathrm{chr}$ & coord & snp_id & ref $b$ & var b & aa change & $\begin{array}{l}\text { Polyphen } \\
\text { prediction }\end{array}$ & $\begin{array}{l}\text { Polyph. } \\
\text { score }\end{array}$ & $\begin{array}{l}\text { snp } \\
\text { exon type }\end{array}$ & ens name & ccds name \\
\hline ZFP352 & 4 & 89890773 & 4T89890773 & $\mathrm{C}$ & $\mathrm{T}$ & $\mathrm{T}->\mathrm{I}$ & benign & 0.417 & NON-SYN & ENSMUSG00000070902 & CCDS18353 \\
\hline LNX1 & 5 & 75023400 & $5 \mathrm{~A} 75023400$ & $\mathrm{~T}$ & A & $\mathrm{N}->\mathrm{Y}$ & benign & 0.355 & NON-SYN & ENSMUSG00000029228 & $\begin{array}{l}\text { CCDS51524,CCDS51522, } \\
\text { CCDS19347,CCDS51523 }\end{array}$ \\
\hline CDHR2 & 13 & 54827683 & 13G54827683 & A & G & $\mathrm{T}->\mathrm{A}$ & benign & 0.291 & NON-SYN & ENSMUSG00000034918 & CCDS36669 \\
\hline LOXHD1 & 18 & 77668681 & 18A77668681 & G & A & $\mathrm{V}->\mathrm{I}$ & benign & 0.239 & NON-SYN & ENSMUSG00000032818 & CCDS50326 \\
\hline GAS8 & 8 & 126048115 & $8 \mathrm{~T} 126048115$ & G & $\mathrm{T}$ & $\mathrm{M}->\mathrm{I}$ & benign & 0.012 & NON-SYN & ENSMUSG00000040220 & CCDS40512 \\
\hline CAR7 & 8 & 107071592 & 8G107071592 & $\mathrm{T}$ & G & $\mathrm{S}->\mathrm{A}$ & benign & 0.01 & NON-SYN & ENSMUSG00000031883 & CCDS22581 \\
\hline F12 & 13 & 55524089 & 13T55524089 & G & $\mathrm{T}$ & $\mathrm{H}->\mathrm{N}$ & benign & 0.01 & NON-SYN & ENSMUSG00000021492 & CCDS36675 \\
\hline BANK1 & 3 & 135897677 & 3C135897677 & $\mathrm{T}$ & $\mathrm{C}$ & $\mathrm{I}->\mathrm{V}$ & benign & 0.006 & NON-SYN & ENSMUSG00000037922 & CCDS38645 \\
\hline JARID2 & 13 & 44997781 & 13A44997781 & $\mathrm{C}$ & A & $\mathrm{H}->\mathrm{N}$ & benign & 0.002 & NON-SYN & ENSMUSG00000038518 & CCDS36646 \\
\hline ВСAP31 & $\mathrm{X}$ & 70931915 & XA70931915 & G & A & $\mathrm{S}->\mathrm{L}$ & benign & 0.002 & NON-SYN & ENSMUSG00000002015 & CCDS30209 \\
\hline NLGN3 & $\mathrm{X}$ & 98502446 & XA98502446 & G & A & $A->T$ & benign & 0.002 & NON-SYN & ENSMUSG00000031302 & CCDS30313 \\
\hline WDR19 & 5 & 65616584 & $5 \mathrm{~A} 65616584$ & G & A & $A->T$ & benign & 0.001 & NON-SYN & ENSMUSG00000037890 & CCDS51509 \\
\hline $\mathrm{CES} 2 \mathrm{G}$ & 8 & 107487837 & $8 \mathrm{~T} 107487837$ & $\mathrm{C}$ & $\mathrm{T}$ & $\mathrm{P}->\mathrm{S}$ & benign & 0.001 & NON-SYN & ENSMUSG00000031877 & CCDS22589 \\
\hline PROM2 & 2 & 127364067 & 2A127364067 & G & A & $\mathrm{T}->\mathrm{M}$ & benign & 0 & NON-SYN & ENSMUSG00000027376 & CCDS16704,CCDS50704 \\
\hline CALU & 6 & 29311393 & 6T29311393 & G & $\mathrm{T}$ & $\mathrm{E}->\mathrm{D}$ & benign & 0 & NON-SYN & ENSMUSG00000029767 & CCDS19958,CCDS19957 \\
\hline PDP2 & 8 & 107117577 & 8G107117577 & $\mathrm{T}$ & G & $\mathrm{C}->\mathrm{G}$ & benign & 0 & NON-SYN & ENSMUSG00000048371 & CCDS22582 \\
\hline TBC1D30 & 10 & 120704059 & 10T120704059 & G & $\mathrm{T}$ & $\mathrm{T}->\mathrm{N}$ & benign & 0 & NON-SYN & ENSMUSG00000052302 & CCDS48704 \\
\hline
\end{tabular}


Table 2

SAMP8-specific mutations and gene descriptions. For the 51 SNVs that are unique to SAMP8 the genes are indicated, the UniProt (Universal Protein resource) name, the name of the human ortholog (homolog, where known), the OMIM entry (Online Mendelian Inheritance in Man, where available), as well as a description of the gene

\begin{tabular}{|c|c|c|c|c|}
\hline Gene name & Uniprot name & Homolog & Omim & Gene description \\
\hline SYT11 & D3YWW9, Q9R0N3 & SYT11 & NO_OMIM & synaptotagmin XI [Source: MGI Symbol; Acc: MGI: 1859547] \\
\hline ARFIP2 & Q8K221 & ARFIP2 & NO_OMIM & ADP-ribosylation factor interacting protein 2 [Source: MGI Symbol; Acc: MGI: 1924182] \\
\hline TPP1 & O89023 & TPP1 & http://omim.org/entry/607998 & tripeptidyl peptidase I [Source: MGI Symbol; Acc: MGI:1336194] \\
\hline NAE1 & Q8VBW6 & NAE1 & http://omim.org/entry/603385 & NEDD8 activating enzyme E1 subunit 1 [Source: MGI Symbol; Acc: MGI: 2384561] \\
\hline TMEM208 & Q9CR96 & TMEM208 & NO_OMIM & transmembrane protein 208 [Source: MGI Symbol; Acc: MGI: 1913570] \\
\hline EDC4 & Q3UJB9 & EDC4 & NO_OMIM & enhancer of mRNA decapping 4 [Source: MGI Symbol; Acc: MGI: 2446249] \\
\hline CNTNAP4 & $\begin{array}{l}\text { D3YWB9, Q8BPP6, } \\
\text { Q99P47 }\end{array}$ & CNTNAP4 & NO_OMIM & contactin associated protein-like 4 [Source: MGI Symbol; Acc: MGI: 2183572] \\
\hline PARP8 & Q3UD82 & PARP8 & NO_OMIM & poly (ADP-ribose) polymerase family, member 8 [Source: MGI Symbol; Acc: MGI: 1098713] \\
\hline 6720463M24RIK & Q8BS90 & BORA & NO_OMIM & RIKEN cDNA 6720463M24 gene [Source: MGI Symbol; Acc: MGI: 1924994] \\
\hline KLF12 & 035738 & KLF12 & http://omim.org/entry/607531 & Kruppel-like factor 12 [Source: MGI Symbol; Acc: MGI: 1333796] \\
\hline SLC12A4 & Q9JIS8 & SLC12A4 & http://omim.org/entry/604119 & solute carrier family 12, member 4 [Source: MGI Symbol; Acc: MGI: 1309465] \\
\hline APBA3 & O88888 & APBA3 & NO_OMIM & $\begin{array}{l}\text { amyloid beta (A4) precursor protein-binding, family A, member } 3 \text { [Source: MGI Symbol; } \\
\text { Acc: MGI: 1888527] }\end{array}$ \\
\hline PQLC3 & Q8C6U2 & PQLC3 & NO_OMIM & PQ loop repeat containing [Source: MGI Symbol; Acc: MGI: 2444067] \\
\hline TMEM55B & Q3TWL2 & TMEM55B & NO_OMIM & transmembrane protein 55b [Source: MGI Symbol; Acc: MGI: 2448501] \\
\hline D15ERTD621E & Q3UVG3 & FAM91A1 & NO_OMIM & $\begin{array}{l}\text { DNA segment, Chr 15, ERATO Doi 621, expressed [Source: MGI Symbol; Acc: MGI: } \\
1277178 \text { ] }\end{array}$ \\
\hline DNAHC8 & Q91X & DNAH8 & NO_OMIM & dynein, axonemal, heavy chain 8 [Source: MGI Symbol; Acc: MGI: 107714] \\
\hline F830016B08RIK & NO_UNIPROT & NO_HOMOLOG & NO_OMIM & RIKEN cDNA F830016B08 gene [Source: MGI Symbol; Acc: MGI: 3588218] \\
\hline FXN & 035943 & FXN & http://omim.org/entry/606829 & frataxin [Source: MGI Symbol; Acc: MGI: 1096879] \\
\hline PTPRD & $\begin{array}{l}\text { E9PVW8,E9Q717, } \\
\text { E9QM93,E9QQ27, } \\
\text { F7C4P7,Q8VBV0 }\end{array}$ & PTPRD & http://omim.org/entry/601598 & protein tyrosine phosphatase, receptor type, D [Source: MGI Symbol; Acc: MGI: 97812] \\
\hline SPCS2 & Q9CYN2 & SPCS2 & NO_OMIM & $\begin{array}{l}\text { signal peptidase complex subunit } 2 \text { homolog (S. cerevisiae) [Source: MGI Symbol; Acc: } \\
\text { MGI: 1913874] }\end{array}$ \\
\hline IRS2 & 81122 & IRS2 & http://omim.org/entry/600797 & insulin receptor substrate 2 [Source: MGI Symbol; Acc: MGI: 109334] \\
\hline ODZ2 & 29WTS5 & ODZ2 & NO_OMIM & odd Oz/ten-m homolog 2 (Drosophila) [Source: MGI Symbol; Acc: MGI: 1345184] \\
\hline HBB-BH2 & B2RVB7 & HBD & NO_OMIM & hemoglobin beta, bh2 [Source: MGI Symbol; Acc: MGI: 96025] \\
\hline ANKRD2 & Q9WV06 & ANKRD2 & http://omim.org/entry/610734 & $\begin{array}{l}\text { ankyrin repeat domain } 2 \text { (stretch responsive muscle) [Source: MGI Symbol; Acc: MGI: } \\
\text { 1861447] }\end{array}$ \\
\hline 4930506M07RIK & Q8K2Q9 & KIAA1598 & NO_OMIM & RIKEN cDNA 4930506M07 gene [Source: MGI Symbol; Acc: MGI: 1918903] \\
\hline TESK1 & O70146 & TESK1 & http://omim.org/entry/601782 & testis specific protein kinase 1 [Source: MGI Symbol; Acc: MGI: 1201675] \\
\hline D630023F18RIK & Q8C3M9 & NO_HOMOLOG & NO_OMIM & RIKEN cDNA D630023F18 gene [Source: MGI Symbol; Acc: MGI: 2138198] \\
\hline PRL8A9 & Q9CQ58 & NO_HOMOLOG & NO_OMIM & prolactin family8, subfamily a, member 9 [Source: MGI Symbol; Acc: MGI: 1914560] \\
\hline $\mathrm{PCDH} 7$ & A2RS43,E9Q2S0 & $\mathrm{PCDH} 7$ & http://omim.org/entry/602988 & protocadherin 7 [Source: MGI Symbol; Acc: MGI: 1860487] \\
\hline IFNA2 & B1AYH7 & NO_HOMOLOG & http://omim.org/entry/147562 & interferon alpha 2 [Source: MGI Symbol; Acc: MGI: 107666] \\
\hline ARHGEF5 & E9Q7D5 & NO_HOMOLOG & http://omim.org/entry/600888 & Rho guanine nucleotide exchange factor (GEF) 5 [Source: MGI Symbol; Acc: MGI: 1858952] \\
\hline LRRC20 & Q8CI70 & LRRC20 & NO_OMIM & leucine rich repeat containing 20 [Source: MGI Symbol; Acc: MGI: 2387182] \\
\hline ZC3H12D & E9Q3F1,E9QNR7 & ZC3H12D & http://omim.org/entry/611106 & zinc finger CCCH type containing 12D [Source: MGI Symbol; Acc: MGI: 3045313] \\
\hline 1700019N19RIK & Q9CQT6 & C10ORF82 & NO_OMIM & RIKEN cDNA 1700019N19 gene [Source: MGI Symbol; Acc: MGI: 1914757] \\
\hline
\end{tabular}


Table 2

(Continued)

\begin{tabular}{|c|c|c|c|c|}
\hline Gene name & Uniprot name & Homolog & Omim & Gene description \\
\hline ZFP352 & A2AML7,Q8VI41 & NO_HOMOLOG & NO_OMIM & zinc finger protein 352 [Source: MGI Symbol; Acc: MGI: 2387418] \\
\hline LNX1 & O70263 & LNX1 & http://omim.org/entry/609732 & ligand of numb-protein X 1 [Source: MGI Symbol; Acc: MGI: 1278335] \\
\hline CDHR2 & E9Q7P9 & CDHR2 & NO_OMIM & cadherin-related family member 2 [Source: MGI Symbol; Acc: MGI: 2687323] \\
\hline LOXHD1 & C8YR32 & LOXHD1 & http://omim.org/entry/613072 & lipoxygenase homology domains 1 [Source: MGI Symbol; Acc: MGI: 1914609] \\
\hline GAS8 & Q60779 & GAS8 & http://omim.org/entry/605178 & growth arrest specific 8 [Source: MGI Symbol; Acc: MGI: 1202386] \\
\hline CAR7 & Q9ERQ8 & CA7 & NO_OMIM & carbonic anhydrase 7 [Source: MGI Symbol; Acc: MGI: 103100] \\
\hline F12 & Q80YC5 & F12 & http://omim.org/entry/610619 & coagulation factor XII (Hageman factor) [Source: MGI Symbol; Acc: MGI: 1891012] \\
\hline BANK1 & $\begin{array}{l}\text { B0F3S4,Q14B54, } \\
\text { Q80VH0 }\end{array}$ & BANK1 & http://omim.org/entry/610292 & B-cell scaffold protein with ankyrin repeats 1 [Source: MGI Symbol; Acc: MGI: 2442120] \\
\hline JARID2 & Q62315 & JARID2 & NO_OMIM & jumonji, AT rich interactive domain 2 [Source: MGI Symbol; Acc: MGI: 104813] \\
\hline BCAP31 & A2ALM8 & BCAP31 & NO_OMIM & B-cell receptor-associated protein 31 [Source: MGI Symbol; Acc: MGI: 1350933] \\
\hline NLGN3 & $\begin{array}{l}\text { A2AGI0,A2AGI2, } \\
\text { A2AGI3,Q8BYM5 }\end{array}$ & NLGN3 & http://omim.org/entry/300336 & neuroligin 3 [Source: MGI Symbol; Acc: MGI: 2444609] \\
\hline WDR19 & Q3UGF1 & WDR19 & http://omim.org/entry/608151 & WD repeat domain 19 [Source: MGI Symbol; Acc: MGI: 2443231] \\
\hline CES2G & E9PV38 & NO_HOMOLOG & NO_OMIM & carboxylesterase 2G [Source: MGI Symbol; Acc: MGI: 1919611] \\
\hline PROM2 & Q3UUY6 & PROM2 & NO_OMIM & prominin 2 [Source: MGI Symbol; Acc: MGI: 2138997] \\
\hline CALU & O35887 & CALU & http://omim.org/entry/603420 & calumenin [Source: MGI Symbol; Acc: MGI: 1097158] \\
\hline PDP2 & Q504M2 & PDP2 & NO_OMIM & $\begin{array}{l}\text { pyruvate dehyrogenase phosphatase catalytic subunit } 2 \text { [Source: MGI Symbol; Acc: MGI: } \\
\text { 1918878] }\end{array}$ \\
\hline TBC1D30 & Q69ZT9 & TBC1D30 & NO_OMIM & TBC1 domain family, member 30 [Source: MGI Symbol; Acc: MGI: 1921944] \\
\hline
\end{tabular}


Table 3

SAMP8-specific mutations and predictions of expression in brain. For the 51 SNVs that are unique to SAMP8 the genes are indicated we assessed the expression in brain as provided by the Allen brain atlas (Allen Brain Atlas [Internet]. Seattle (WA): Allen Institute for Brain Science. Copyright $\odot$ 2009. Available from: http://www.brain-map.org): CTX, cortex; Hip, hippocampus; Olfact, olfactory bulb; Hypo, hypothalamus; Crb, cerebellum; Thal, thalamus; pons, pallidum, and medulla. The MGI (Mouse Genome Informatics) link provides additional information on the gene

\begin{tabular}{|c|c|c|c|}
\hline Gene name & Expression in brain & Allen atlas link & MGI Link \\
\hline SYT11 & 11 brain & $\begin{array}{l}\text { http://mouse.brain-map.org/experiment/show/ } \\
2649\end{array}$ & $\begin{array}{l}\text { http://www.informatics.jax.org/marker/ } \\
\text { MGI:1859547 }\end{array}$ \\
\hline ARFIP2 & CTX \& Hip & $\begin{array}{l}\text { http://mouse.brain-map.org/experiment/show/ } \\
74990537\end{array}$ & $\begin{array}{l}\text { http://www.informatics.jax.org/marker/ } \\
\text { MGI:1924182 }\end{array}$ \\
\hline TPP1 & CTX \& Hip & $\begin{array}{l}\text { http://mouse.brain-map.org/experiment/show/ } \\
68148756\end{array}$ & $\begin{array}{l}\text { http://www.informatics.jax.org/marker/ } \\
\text { MGI:1336194 }\end{array}$ \\
\hline NAE1 & Slight in CTX & $\begin{array}{l}\text { http://mouse.brain-map.org/experiment/show/ } \\
76098392\end{array}$ & $\begin{array}{l}\text { http://www.informatics.jax.org/marker/ } \\
\text { MGI:2384561 }\end{array}$ \\
\hline TMEM208 & No expression & $\begin{array}{l}\text { http://mouse.brain-map.org/experiment/show/ } \\
69015745\end{array}$ & $\begin{array}{l}\text { http://www.informatics.jax.org/marker/ } \\
\text { MGI:1913570 }\end{array}$ \\
\hline EDC4 & CTX \& Hip & $\begin{array}{l}\text { http://mouse.brain-map.org/experiment/show/ } \\
68911011\end{array}$ & $\begin{array}{l}\text { http://www.informatics.jax.org/marker/ } \\
\text { MGI:2446249 }\end{array}$ \\
\hline CNTNAP4 & Very slight in Hip \& Olfact & $\begin{array}{l}\text { http://mouse.brain-map.org/experiment/show/ } \\
68196926\end{array}$ & $\begin{array}{l}\text { http://www.informatics.jax.org/marker/ } \\
\text { MGI:2183572 }\end{array}$ \\
\hline PARP8 & CTX, Hip, \& Hypo & $\begin{array}{l}\text { http://mouse.brain-map.org/experiment/show/ } \\
68445676\end{array}$ & $\begin{array}{l}\text { http://www.informatics.jax.org/marker/ } \\
\text { MGI:1098713 }\end{array}$ \\
\hline 6720463M24RIK & No expression & $\begin{array}{l}\text { http://mouse.brain-map.org/experiment/show/ } \\
68797816\end{array}$ & $\begin{array}{l}\text { http://www.informatics.jax.org/marker/ } \\
\text { MGI:1924994 }\end{array}$ \\
\hline KLF12 & Slight in CTX \& Olfact & $\begin{array}{l}\text { http://mouse.brain-map.org/experiment/show/ } \\
69289279\end{array}$ & $\begin{array}{l}\text { http://www.informatics.jax.org/marker/ } \\
\text { MGI:1333796 }\end{array}$ \\
\hline SLC12A4 & No expression & $\begin{array}{l}\text { http://mouse.brain-map.org/experiment/show/ } \\
69873797\end{array}$ & $\begin{array}{l}\text { http://www.informatics.jax.org/marker/ } \\
\text { MGI:1309465 }\end{array}$ \\
\hline APBA3 & Very slight in CTX & $\begin{array}{l}\text { http://mouse.brain-map.org/experiment/show/ } \\
68442913\end{array}$ & $\begin{array}{l}\text { http://www.informatics.jax.org/marker/ } \\
\text { MGI:1888527 }\end{array}$ \\
\hline PQLC3 & No data & & $\begin{array}{l}\text { http://www.informatics.jax.org/marker/ } \\
\text { MGI:2444067 }\end{array}$ \\
\hline TMEM55B & CTX, Thal, Pons, Medulla & $\begin{array}{l}\text { http://mouse.brain-map.org/experiment/show/ } \\
69529095\end{array}$ & $\begin{array}{l}\text { http://www.informatics.jax.org/marker/ } \\
\text { MGI:2448501 }\end{array}$ \\
\hline D15ERTD621E & No expression & $\begin{array}{l}\text { http://mouse.brain-map.org/experiment/show/ } \\
\quad 71723906\end{array}$ & $\begin{array}{l}\text { http://www.informatics.jax.org/marker/ } \\
\text { MGI:1277178 }\end{array}$ \\
\hline DNAHC8 & No ex & $\begin{array}{l}\text { http://mouse.brain-map.org/experiment/show/ } \\
69626945\end{array}$ & $\begin{array}{l}\text { http://www.informatics.jax.org/marker/ } \\
\text { MGI:107714 }\end{array}$ \\
\hline F830016B08RIK & No data & & $\begin{array}{l}\text { http://www.informatics.jax.org/marker/ } \\
\text { MGI:3588218 }\end{array}$ \\
\hline FXN & Very high, all brain & $\begin{array}{l}\text { http://mouse.brain-map.org/experiment/show/ } \\
69672575\end{array}$ & $\begin{array}{l}\text { http://www.informatics.jax.org/marker/ } \\
\text { MGI:1096879 }\end{array}$ \\
\hline PTPRD & CTX, Hip \& Thal & $\begin{array}{l}\text { http://mouse.brain-map.org/experiment/show/ } \\
\quad 855\end{array}$ & $\begin{array}{l}\text { http://www.informatics.jax.org/marker/ } \\
\text { MGI:97812 }\end{array}$ \\
\hline SPCS2 & CTX, Pallidum \& Hypo & $\begin{array}{l}\text { http://mouse.brain-map.org/experiment/show/ } \\
68667312\end{array}$ & $\begin{array}{l}\text { http://www.informatics.jax.org/marker/ } \\
\text { MGI:1913874 }\end{array}$ \\
\hline IRS2 & Very slight in Hip \& Thal & $\begin{array}{l}\text { http://mouse.brain-map.org/experiment/show/ } \\
71211707\end{array}$ & $\begin{array}{l}\text { http://www.informatics.jax.org/marker/ } \\
\text { MGI:109334 }\end{array}$ \\
\hline ODZ2 & Very slight in Hip only & $\begin{array}{l}\text { http://mouse.brain-map.org/experiment/show/ } \\
79591631\end{array}$ & $\begin{array}{l}\text { http://www.informatics.jax.org/marker/ } \\
\text { MGI:1345184 }\end{array}$ \\
\hline HBB-BH2 & No data & & $\begin{array}{l}\text { http://www.informatics.jax.org/marker/ } \\
\text { MGI:96025 }\end{array}$ \\
\hline ANKRD2 & No ex & $\begin{array}{l}\text { http://mouse.brain-map.org/experiment/show/ } \\
69526647\end{array}$ & $\begin{array}{l}\text { http://www.informatics.jax.org/marker/ } \\
\text { MGI:1861447 }\end{array}$ \\
\hline 4930506M07RIK & CTX \& Hip & $\begin{array}{l}\text { http://mouse.brain-map.org/experiment/show/ } \\
275675\end{array}$ & $\begin{array}{l}\text { http://www.informatics.jax.org/marker/ } \\
\text { MGI:1918903 }\end{array}$ \\
\hline TESK1 & Slight in CTX, Hip \& Crb & $\begin{array}{l}\text { http://mouse.brain-map.org/experiment/show/ } \\
69980268\end{array}$ & $\begin{array}{l}\text { http://www.informatics.jax.org/marker/ } \\
\text { MGI:1201675 }\end{array}$ \\
\hline D630023F18RIK & No expression & $\begin{array}{l}\text { http://mouse.brain-map.org/experiment/show/ } \\
69609007\end{array}$ & $\begin{array}{l}\text { http://www.informatics.jax.org/marker/ } \\
\text { MGI:2138198 }\end{array}$ \\
\hline PRL8A9 & No expression & $\begin{array}{l}\text { http://mouse.brain-map.org/experiment/show/ } \\
71656664\end{array}$ & $\begin{array}{l}\text { http://www.informatics.jax.org/marker/ } \\
\text { MGI:1914560 }\end{array}$ \\
\hline PCDH7 & Very slight in CTX & $\begin{array}{l}\text { http://mouse.brain-map.org/experiment/show/ } \\
69782790\end{array}$ & $\begin{array}{l}\text { http://www.informatics.jax.org/marker/ } \\
\text { MGI:1860487 }\end{array}$ \\
\hline
\end{tabular}




\begin{tabular}{|c|c|c|c|}
\hline Gene name & Expression in brain & Allen atlas link & MGI Link \\
\hline IFNA2 & No data & $\begin{array}{l}\text { http://mouse.brain-map.org/experiment/show/ } \\
69526838\end{array}$ & $\begin{array}{l}\text { http://www.informatics.jax.org/marker/ } \\
\text { MGI:107666 }\end{array}$ \\
\hline ARHGEF5 & No expression & $\begin{array}{l}\text { http://mouse.brain-map.org/experiment/show/ } \\
69526838\end{array}$ & $\begin{array}{l}\text { http://www.informatics.jax.org/marker/ } \\
\text { MGI:1858952 }\end{array}$ \\
\hline LRRC20 & Very slight in Crb \& Olfact & $\begin{array}{l}\text { http://mouse.brain-map.org/experiment/show/ } \\
68797500\end{array}$ & $\begin{array}{l}\text { http://www.informatics.jax.org/marker/ } \\
\text { MGI:2387182 }\end{array}$ \\
\hline ZC3H12D & No expression & $\begin{array}{l}\text { http://mouse.brain-map.org/experiment/show/ } \\
71809097\end{array}$ & $\begin{array}{l}\text { http://www.informatics.jax.org/marker/ } \\
\text { MGI:3045313 }\end{array}$ \\
\hline 1700019N19RIK & No expression & $\begin{array}{l}\text { http://mouse.brain-map.org/experiment/show/ } \\
69114465\end{array}$ & $\begin{array}{l}\text { http://www.informatics.jax.org/marker/ } \\
\text { MGI:1914757 }\end{array}$ \\
\hline ZFP352 & No expression & $\begin{array}{l}\text { http://mouse.brain-map.org/experiment/show/ } \\
70785732\end{array}$ & $\begin{array}{l}\text { http://www.informatics.jax.org/marker/ } \\
\text { MGI:2387418 }\end{array}$ \\
\hline LNX1 & No expression & $\begin{array}{l}\text { http://mouse.brain-map.org/experiment/show/ } \\
74277745\end{array}$ & $\begin{array}{l}\text { http://www.informatics.jax.org/marker/ } \\
\text { MGI:1278335 }\end{array}$ \\
\hline CDHR2 & No expression & $\begin{array}{l}\text { http://mouse.brain-map.org/experiment/show/ } \\
69529107\end{array}$ & $\begin{array}{l}\text { http://www.informatics.jax.org/marker/ } \\
\text { MGI:2687323 }\end{array}$ \\
\hline LOXHD1 & No expression & $\begin{array}{l}\text { http://mouse.brain-map.org/experiment/show/ } \\
73514737\end{array}$ & $\begin{array}{l}\text { http://www.informatics.jax.org/marker/ } \\
\text { MGI:1914609 }\end{array}$ \\
\hline GAS8 & CTX, Hip \& Thal & $\begin{array}{l}\text { http://mouse.brain-map.org/experiment/show/ } \\
74990538\end{array}$ & $\begin{array}{l}\text { http://www.informatics.jax.org/marker/ } \\
\text { MGI:1202386 }\end{array}$ \\
\hline CAR7 & No expression & $\begin{array}{l}\text { http://mouse.brain-map.org/experiment/show/ } \\
71496276\end{array}$ & $\begin{array}{l}\text { http://www.informatics.jax.org/marker/ } \\
\text { MGI:103100 }\end{array}$ \\
\hline F12 & No data & & $\begin{array}{l}\text { http://www.informatics.jax.org/marker/ } \\
\text { MGI:1891012 }\end{array}$ \\
\hline BANK1 & Slight in CTX & $\begin{array}{l}\text { http://mouse.brain-map.org/experiment/show/ } \\
69528076\end{array}$ & $\begin{array}{l}\text { http://www.informatics.jax.org/marker/ } \\
\text { MGI:2442120 }\end{array}$ \\
\hline JARID2 & Slight in olfact & $\begin{array}{l}\text { http://mouse.brain-map.org/experiment/show/ } \\
\quad 605\end{array}$ & $\begin{array}{l}\text { http://www.informatics.jax.org/marker/ } \\
\text { MGI:104813 }\end{array}$ \\
\hline BCAP31 & CTX, Pons \& Medulla & $\begin{array}{l}\text { http://mouse.brain-map.org/experiment/show/ } \\
79544798\end{array}$ & $\begin{array}{l}\text { http://www.informatics.jax.org/marker/ } \\
\text { MGI:1350933 }\end{array}$ \\
\hline NLGN3 & High all brain & $\begin{array}{l}\text { http://mouse.brain-map.org/experiment/show/ } \\
70300559\end{array}$ & $\begin{array}{l}\text { http://www.informatics.jax.org/marker/ } \\
\text { MGI:2444609 }\end{array}$ \\
\hline WDR19 & No expression & $\begin{array}{l}\text { http://mouse.brain-map.org/experiment/show/ } \\
70194988\end{array}$ & $\begin{array}{l}\text { http://www.informatics.jax.org/marker/ } \\
\text { MGI:2443231 }\end{array}$ \\
\hline CES2G & Very slight in olfact & $\begin{array}{l}\text { http://mouse.brain-map.org/experiment/show/ } \\
68445053\end{array}$ & $\begin{array}{l}\text { http://www.informatics.jax.org/marker/ } \\
\text { MGI:1919611 }\end{array}$ \\
\hline PROM2 & No expression & $\begin{array}{l}\text { http://mouse.brain-map.org/experiment/show/ } \\
68498519\end{array}$ & $\begin{array}{l}\text { http://www.informatics.jax.org/marker/ } \\
\text { MGI:2138997 }\end{array}$ \\
\hline CALU & No expression & $\begin{array}{l}\text { http://mouse.brain-map.org/experiment/show/ } \\
69013426\end{array}$ & $\begin{array}{l}\text { http://www.informatics.jax.org/marker/ } \\
\text { MGI:1097158 }\end{array}$ \\
\hline PDP2 & No expression & $\begin{array}{l}\text { http://mouse.brain-map.org/experiment/show/ } \\
70299983\end{array}$ & $\begin{array}{l}\text { http://www.informatics.jax.org/marker/ } \\
\text { MGI:1918878 }\end{array}$ \\
\hline TBC1D30 & Very slight in CTX & $\begin{array}{l}\text { http://mouse.brain-map.org/experiment/show/ } \\
72283432\end{array}$ & $\begin{array}{l}\text { http://www.informatics.jax.org/marker/ } \\
\text { MGI:1921944 }\end{array}$ \\
\hline
\end{tabular}

study, we also identified the enhancer of decapping Edc4 [41], and Klf12 that encodes Kruppel-like Factor 12 , a member of a zinc finger protein family that regulates gene transcription [42]. Interestingly, a recent transcriptomic analysis of tau mutant mice revealed a deregulation of several transcription factors including Zranb1 (a Zinc finger-containing protein) and SFPQ (splicing factor proline/glutamine rich), also known as PSF (Polypyrimidine tract-binding protein-associated Splicing Factor) [43]. Validation of SFPQ revealed that in $\mathrm{AD}$ the transcription factor is relocalized from the nucleus to the cytoplasm [43].
Among the genes with brain expression are several that encode enzymes such as kinases and phosphatases (PTPRD, TESK1, TMEM55B) that could potentially regulate the phosphorylation of cytoskeletal proteins such as tau. TESK1 is particularly interesting as together with Spred1, it is an interaction partner of the kinase MARKK/TAO1 that links the microtubule and actin cytoskeleton [44]. With a SNV in the gene encoding the signal peptidase SPCS2, more fundamental processes could be affected in the SAMP8 mice as depletion of SPC3 in yeast leads to impaired secretion and the accumulation of secretory proteins [45]. TPPI 
encodes the lysosomal enzyme tripeptidyl-peptidase 1, and mutations in this gene cause a form of spinocerebellar ataxia, with patients having a shortened lifespan. It might be possible, that the SNV found for TPP in the SAMP8 mice contributes to the shortened lifespan that characterizes the strain [46]. A SNV was also found in the FXN gene, for which a trinucleotide expansion in human causes yet another ataxia, Friedreich ataxia [47].

Finally, IRS2 (insulin receptor signaling 2) is an interesting molecule with central functions including the regulation of mammalian lifespan and nutrient homeostasis [48], glucose metabolism [49], as well as mitochondrial functions and the dealing with oxidative stress [50]. Moreover, IRS2 is a negative regulator of memory formation and has been shown to impair NMDA receptor-dependent long-term potentiation [51, 52]. All of these functions are impaired in the SAMP8 mice suggesting that an impaired IRS2 function could potentially contribute to the SAMP8 phenotype.

Having identified a total of 51 SNVs by exome sequencing that discriminate SAMP8 and SAMR1, we anticipate that these will allow a phenotypic discrimination, especially as it is evident from our list that several of the SNVs are within genes that in principal could contribute to the SAMP8 phenotype. It is reasonable to assume that a subset of the SNVs causes either changes in protein levels, stability, subcellular localization or posttransational modification of the encoded proteins, which can be detected provided that suitable antibodies are available. The SNVs should be also useful in monitoring the SAMP8 strain to ensure that there is no genetic drift in any given colony. Furthermore, it may be possible to establish sub-lines that inherit some of the SNVs and hence result in a segregation of a subset of the phenotypic traits that affect selected systems such as the brain or the immune system.

As mentioned above, SAMP8 mice do not present with typical plaques and tangles, although the accumulation of $A \beta$ and hyperphosphorylated tau has been reported $[23,26]$. In order to exploit SAMP8 mice for $\mathrm{AD}$ research a further possibility is to cross the SAMP8 mice with either $A \beta$ plaque-forming or tau tangle-forming transgenic mice. Here, for example, the question can be asked whether a tau pathology such as that of P301L tau mutant mice with a memory phenotype [53] or of K369I mutant mice with neuronal loss and a motor phenotype $[54,55]$ would be accelerated by the presence of distinct SAMP8 SNVs. Alternatively one could ask whether removing or reducing tau would ameliorate some of the phenotypes that charac- terize the SAMP8 mice [56]. In conclusion, we believe that our data contribute to ascertaining SAMP8 mice as a suitable model system to study aging and dementia.

\section{ACKNOWLEDGMENTS}

This study was supported by the Estate of Dr. Clem Jones AO and by grants from the Australian Research Council and the National Health and Medical Research Council of Australia to JG, as well as the Phillip Jacoby Scholarship in Alzheimer's Dementia Research to FD. Sequencing and bioinformatic analyses were supported by the Australian Super Science Initiative funded through the Education Investment Fund to the APF.

Authors' disclosures available online (http://www.jalz.com/disclosures/view.php?id=1726).

\section{SUPPLEMENTARY MATERIAL}

Supplementary material can be found here: http:// dx.doi.org/10.3233/JAD-130089

\section{REFERENCES}

[1] Ballard C, Gauthier S, Corbett A, Brayne C, Aarsland D, Jones E (2011) Alzheimer's disease. Lancet 377, 1019-1031.

[2] Gotz J, Ittner LM (2008) Animal models of Alzheimer's disease and frontotemporal dementia. Nat Rev Neurosci 9 , 532-544.

[3] Del Valle J, Bayod S, Camins A, Beas-Zarate C, VelazquezZamora DA, Gonzalez-Burgos I, Pallas M (2012) Dendritic spine abnormalities in hippocampal CA1 pyramidal neurons underlying memory deficits in the SAMP8 mouse model of Alzheimer's disease. J Alzheimers Dis 32, 233-240.

[4] Pallas M, Camins A, Smith MA, Perry G, Lee HG, Casadesus G (2008) From aging to Alzheimer's disease: Unveiling "the switch" with the senescence-accelerated mouse model (SAMP8). J Alzheimers Dis 15, 615-624.

[5] Takeda T (1999) Senescence-accelerated mouse (SAM): A biogerontological resource in aging research. Neurobiol Aging 20, 105-110.

[6] Shimada A, Hasegawa-Ishii S (2011) Senescence-accelerated mice (SAMs) as a model for brain aging and immunosenescence. Aging Dis 2, 414-435.

[7] Flood JF, Morley JE (1998) Learning and memory in the SAMP8 mouse. Neurosci Biobehav Rev 22, 1-20.

[8] Cheng H, Yu J, Jiang Z, Zhang X, Liu C, Peng Y, Chen F, Qu Y, Jia Y, Tian Q, Xiao C, Chu Q, Nie K, Kan B, Hu X, Han J (2008) Acupuncture improves cognitive deficits and regulates the brain cell proliferation of SAMP8 mice. Neurosci Lett $\mathbf{4 3 2}$, 111-116.

[9] Flood JF, Farr SA, Uezu K, Morley JE (1998) Age-related changes in septal serotonergic, GABAergic and glutamatergic facilitation of retention in SAMP8 mice. Mech Ageing Dev 105, 173-188.

[10] Ikegami S, Shumiya S, Kawamura H (1992) Age-related changes in radial-arm maze learning and basal forebrain 
cholinergic systems in senescence accelerated mice (SAM). Behav Brain Res 51, 15-22.

[11] Chen GH, Wang YJ, Wang XM, Zhou JN (2004) Accelerated senescence prone mouse- 8 shows early onset of deficits in spatial learning and memory in the radial six-arm water maze. Physiol Behav 82, 883-890.

[12] McGaugh JL (1966) Time-dependent processes in memory storage. Science 153, 1351-1358.

[13] Senechal Y, Kelly PH, Dev KK (2008) Amyloid precursor protein knockout mice show age-dependent deficits in passive avoidance learning. Behav Brain Res 186, 126-132.

[14] Miyamoto M (1994) [Experimental techniques for developing new drugs acting on dementia (8)-Characteristics of behavioral disorders in senescence-accelerated mouse (SAMP8): Possible animal model for dementia]. Nihon Shinkei Seishin Yakurigaku Zasshi 14, 323-335.

[15] Miyamoto M (1997) Characteristics of age-related behavioral changes in senescence-accelerated mouse SAMP8 and SAMP10. Exp Gerontol 32, 139-148.

[16] Schmitt K, Grimm A, Kazmierczak A, Strosznajder JB, Gotz J, Eckert A (2012) Insights into mitochondrial dysfunction: Aging, amyloid-beta, and tau-A deleterious trio. Antioxid Redox Signal 16, 1456-1466.

[17] Kurokawa T, Asada S, Nishitani S, Hazeki O (2001) Agerelated changes in manganese superoxide dismutase activity in the cerebral cortex of senescence-accelerated prone and resistant mouse. Neurosci Lett 298, 135-138.

[18] Sato E, Oda N, Ozaki N, Hashimoto S, Kurokawa T, Ishibashi S (1996) Early and transient increase in oxidative stress in the cerebral cortex of senescence-accelerated mouse. Mech Ageing Dev 86, 105-114.

[19] Okatani Y, Wakatsuki A, Reiter RJ, Miyahara Y (2002) Melatonin reduces oxidative damage of neural lipids and proteins in senescence-accelerated mouse. Neurobiol Aging 23, 639-644.

[20] Yasui F, Ishibashi M, Matsugo S, Kojo S, Oomura Y, Sasaki K (2003) Brain lipid hydroperoxide level increases in senescence-accelerated mice at an early age. Neurosci Lett 350, 66-68.

[21] Kurokawa T, Sato E, Inoue A, Ishibashi S (1996) Evidence that glucose metabolism is decreased in the cerebrum of aged female senescence-accelerated mouse; possible involvement of a low hexokinase activity. Neurosci Lett 214, 45-48.

[22] Kitamura Y, Zhao XH, Ohnuki T, Nomura Y (1989) Ligand-binding characteristics of $[3 \mathrm{H}] \mathrm{QNB},[3 \mathrm{H}]$ prazosin, $[3 \mathrm{H}]$ rauwolscine, $[3 \mathrm{H}] \mathrm{TCP}$ and $[3 \mathrm{H}]$ nitrendipine to cerebral cortical and hippocampal membranes of senescence accelerated mouse. Neurosci Lett 106, 334-338.

[23] Canudas AM, Gutierrez-Cuesta J, Rodriguez MI, AcunaCastroviejo D, Sureda FX, Camins A, Pallas M (2005) Hyperphosphorylation of microtubule-associated protein tau in senescence-accelerated mouse (SAM). Mech Ageing Dev 126, 1300-1304.

[24] Gotz J, Gladbach A, Pennanen L, van Eersel J, Schild A, David D, Ittner LM (2010) Animal models reveal role for tau phosphorylation in human disease. Biochim Biophys Acta 1802, 860-871.

[25] Gutierrez-Cuesta J, Sureda FX, Romeu M, Canudas AM, Caballero B, Coto-Montes A, Camins A, Pallas M (2007) Chronic administration of melatonin reduces cerebral injury biomarkers in SAMP8. J Pineal Res 42, 394-402.

[26] Takemura M, Nakamura S, Akiguchi I, Ueno M, Oka N, Ishikawa S, Shimada A, Kimura J, Takeda T (1993) Beta/A4 proteinlike immunoreactive granular structures in the brain of senescence-accelerated mouse. Am J Pathol 142, 1887 1897.
[27] Fukunari A, Kato A, Sakai Y, Yoshimoto T, Ishiura S, Suzuki K, Nakajima T (1994) Colocalization of prolyl endopeptidase and amyloid beta-peptide in brains of senescence-accelerated mouse. Neurosci Lett 176, 201-204.

[28] Kumar VB, Farr SA, Flood JF, Kamlesh V, Franko M, Banks WA, Morley JE (2000) Site-directed antisense oligonucleotide decreases the expression of amyloid precursor protein and reverses deficits in learning and memory in aged SAMP8 mice. Peptides 21, 1769-1775.

[29] Morley JE, Kumar VB, Bernardo AE, Farr SA, Uezu K, Tumosa N, Flood JF (2000) Beta-amyloid precursor polypeptide in SAMP8 mice affects learning and memory. Peptides 21, 1761-1767.

[30] Nomura Y, Yamanaka Y, Kitamura Y, Arima T, Ohnuki T, Oomura Y, Sasaki K, Nagashima K, Ihara Y (1996) Senescence-accelerated mouse. Neurochemical studies on aging. Ann N Y Acad Sci 786, 410-418.

[31] Sureda FX, Gutierrez-Cuesta J, Romeu M, Mulero M, Canudas AM, Camins A, Mallol J, Pallas M (2006) Changes in oxidative stress parameters and neurodegeneration markers in the brain of the senescence-accelerated mice SAMP-8. Exp Gerontol 41, 360-367.

[32] Andrews TD, Whittle B, Field MA, Balakishnan B, Zhang Y, Shao Y, Cho V, Kirk M, Singh M, Xia Y, Hager J, Winslade S, Sjollema G, Beutler B, Enders A, Goodnow CC (2012) Massively parallel sequencing of the mouse exome to accurately identify rare, induced mutations: An immediate source for thousands of new mouse models. Open Biol 2, 120061.

[33] Lim YA, Giese M, Shepherd C, Halliday G, Kobayashi M, Takamatsu K, Staufenbiel M, Eckert A, Gotz J (2012) Role of hippocalcin in mediating Abeta toxicity. Biochim Biophys Acta 1822, 1247-1257.

[34] Li H, Durbin R (2009) Fast and accurate short read alignment with Burrows-Wheeler transform. Bioinformatics 25, 17541760.

[35] Li H, Handsaker B, Wysoker A, Fennell T, Ruan J, Homer N, Marth G, Abecasis G, Durbin R (2009) The Sequence Alignment/Map format and SAMtools. Bioinformatics 25, 2078-2079.

[36] Wang K, Li M, Hakonarson H (2010) ANNOVAR: Functional annotation of genetic variants from high-throughput sequencing data. Nucleic Acids Res 38, e164.

[37] Adzhubei IA, Schmidt S, Peshkin L, Ramensky VE, Gerasimova A, Bork P, Kondrashov AS, Sunyaev SR (2010) A method and server for predicting damaging missense mutations. Nat Methods 7, 248-249.

[38] Morley JE, Armbrecht HJ, Farr SA, Kumar VB (2012) The senescence accelerated mouse (SAMP8) as a model for oxidative stress and Alzheimer's disease. Biochim Biophys Acta 1822, 650-656.

[39] Swistowski A, Zhang Q, Orcholski ME, Crippen D, Vitelli C, Kurakin A, Bredesen DE (2009) Novel mediators of amyloid precursor protein signaling. J Neurosci 29, 15703-15712.

[40] Schonrock N, Matamales M, Ittner LM, Gotz J (2011) MicroRNA networks surrounding APP and amyloid-beta metabolism - Implications for Alzheimer's disease. Exp Neurol 235, 447-454.

[41] Glasmacher E, Hoefig KP, Vogel KU, Rath N, Du L, Wolf C, Kremmer E, Wang X, Heissmeyer V (2010) Roquin binds inducible costimulator mRNA and effectors of mRNA decay to induce microRNA-independent post-transcriptional repression. Nat Immunol 11, 725-733.

[42] Ko JL, Liu HC, Loh HH (2003) Role of an AP-2-like element in transcriptional regulation of mouse mu-opioid receptor gene. Brain Res Mol Brain Res 112, 153-162. 
[43] Ke Y, Dramiga J, Schutz U, Kril JJ, Ittner LM, Schroder H, Gotz J (2012) Tau-mediated nuclear depletion and cytoplasmic accumulation of SFPQ in Alzheimer's and Pick's disease. PLoS One 7, e35678.

[44] Johne C, Matenia D, Li XY, Timm T, Balusamy K, Mandelkow EM (2008) Spred1 and TESK1-two new interaction partners of the kinase MARKK/TAO1 that link the microtubule and actin cytoskeleton. Mol Biol Cell 19, 1391-1403.

[45] Meyer HA, Hartmann E (1997) The yeast SPC22/23 homolog $\mathrm{Spc} 3 \mathrm{p}$ is essential for signal peptidase activity. $\mathrm{J}$ Biol Chem 272, 13159-13164.

[46] Sun Y, Almomani R, Breedveld GJ, Santen GW, Aten E, Lefeber DJ, Hoff JI, Brusse E, Verheijen FW, Verdijk RM, Kriek M, Oostra B, Breuning MH, Losekoot M, den Dunnen JT, van de Warrenburg BP, Maat-Kievit AJ (2013) Autosomal recessive spinocerebellar ataxia 7 (SCAR7) is caused by variants in TPP1, the gene involved in classic late-infantile neuronal ceroid lipofuscinosis 2 disease (CLN2 Disease). Hum Mutat 34, 706-713.

[47] Delatycki MB, Corben LA (2012) Clinical features of Friedreich ataxia. J Child Neurol 27, 1133-1137.

[48] Taguchi A, Wartschow LM, White MF (2007) Brain IRS2 signaling coordinates life span and nutrient homeostasis. Science 317, 369-372.

[49] Choudhury AI, Heffron H, Smith MA, Al-Qassab H, Xu AW, Selman C, Simmgen M, Clements M, Claret M, Maccoll G, Bedford DC, Hisadome K, Diakonov I, Moosajee V, Bell JD, Speakman JR, Batterham RL, Barsh GS, Ashford ML, Withers DJ (2005) The role of insulin receptor substrate 2 in hypothalamic and beta cell function. J Clin Invest 115, 940-950.
[50] Sadagurski M, Cheng Z, Rozzo A, Palazzolo I, Kelley GR, Dong X, Krainc D, White MF (2011) IRS2 increases mitochondrial dysfunction and oxidative stress in a mouse model of Huntington disease. J Clin Invest 121, 4070-4081.

[51] Martin ED, Sanchez-Perez A, Trejo JL, Martin-Aldana JA, Cano Jaimez M, Pons S, Acosta Umanzor C, Menes L, White MF, Burks DJ (2012) IRS-2 Deficiency impairs NMDA receptor-dependent long-term potentiation. Cereb Cortex 22, 1717-1727.

[52] Irvine EE, Drinkwater L, Radwanska K, Al-Qassab H, Smith MA, O’Brien M, Kielar C, Choudhury AI, Krauss S, Cooper JD, Withers DJ, Giese KP (2011) Insulin receptor substrate 2 is a negative regulator of memory formation. Learn Mem $\mathbf{1 8}$, 375-383.

[53] Pennanen L, Wolfer DP, Nitsch RM, Gotz J (2006) Impaired spatial reference memory and increased exploratory behavior in $\mathrm{P} 301 \mathrm{~L}$ tau transgenic mice. Genes Brain Behav 5, 369-379.

[54] Liu X, Dobbie M, Tunningley R, Whittle B, Zhang Y, Ittner LM, Gotz J (2011) ENU mutagenesis screen to establish motor phenotypes in wild-type mice and modifiers of a preexisting motor phenotype in tau mutant mice. $J$ Biomed Biotechno 2011, 130947.

[55] Ittner LM, Ke YD, Gotz J (2009) Phosphorylated Tau Interacts with c-Jun N-terminal Kinase-interacting Protein 1 (JIP1) in Alzheimer Disease. J Biol Chem 284, 20909-20916.

[56] Ittner LM, Ke YD, Delerue F, Bi M, Gladbach A, van Eersel J, Wolfing H, Chieng BC, Christie MJ, Napier IA, Eckert A, Staufenbiel M, Hardeman E, Gotz J (2010) Dendritic function of tau mediates amyloid-beta toxicity in Alzheimer's disease mouse models. Cell 142, 387-397. 